CLINICAL STUDY

\title{
Adrenal function during coronary artery bypass grafting
}

\author{
Christoph Henzen, Richard Kobza, Birgit Schwaller-Protzmann, Peter Stulz ${ }^{1}$ and Verena A Briner \\ Department of Internal Medicine and ${ }^{1}$ Department of Cardiothoracic Surgery, Kantonsspital, CH-6000 Luzern 16, Switzerland \\ (Correspondence should be addressed to C Henzen, Medizinische Klinik, Kantonsspital, CH-6000 Luzern 16, Switzerland; \\ Email: Christoph.Henzen@ksl.ch)
}

\begin{abstract}
Objective: To assess adrenal function in patients undergoing coronary artery bypass grafting (CABG) by means of the low-dose $(1 \mu \mathrm{g})$ ACTH test, and to correlate the adrenal function with clinical outcome.

Methods: During a 5-month period we prospectively included 45 patients undergoing elective CABG with cardiopulmonary bypass and without symptoms of endocrine disease. Low-dose $(1 \mu \mathrm{g})$ ACTH tests were performed on the day before surgery (day -1 ), immediately after the operation (day 0 ), on the two subsequent days in the intensive care unit (day 1 and day 2), and on the day of discharge from the hospital. A number of clinical, hemodynamic and laboratory parameters were monitored throughout.

Results: On day $-1,75 \%$ of the study patients had normal stimulated plasma cortisol concentrations. Eleven patients $(25 \%)$ had an impaired adrenal response to $1 \mu \mathrm{g}$ ACTH. The stimulated plasma cortisol concentrations in patients who had an inadequate adrenal response on day -1 remained significantly reduced on day $1(756 \pm 205$ vs $949 \pm 259 \mathrm{nmol} / \mathrm{l}, P=0.03)$ (mean \pm S.D.), day $2(644$ $(580-793)$ vs $885(713-1087), P=0.03)$ (median (interquartile range)), and on the day of discharge $(698 \pm 201$ vs $854 \pm 186, P=0.05)$. In patients with a normal adrenal response in the preoperative setting peak cortisol concentrations were reached on day 1 , in patients with a blunted adrenal response they were reached on day 2. There were significant correlations between the stimulated plasma cortisol concentrations and the blood loss $(r=-0.50, P=0.002)$ and volume balance $(r=0.41, P=0.015)$.

Conclusions: Occult (partial) adrenal insufficiency is common in patients undergoing CABG who are otherwise asymptomatic as regards endocrine disease. The adrenal function in these patients differs both in the magnitude of cortisol response to ACTH and in the time course, with significantly delayed peak cortisol concentrations. Adequate regulation of volume balance and the amount of blood loss seem to correlate with adequacy of adrenal function.
\end{abstract}

European Journal of Endocrinology 148 663-668

\section{Introduction}

Cortisol has vital circulatory effects in stress response, and even a mild adrenal insufficiency can be hazardous in critical illness or major surgery (1). However, a random plasma cortisol measurement does not reliably identify the patients who may develop symptoms and signs of acute addisonian crisis (i.e. dehydration, fever, confusion, nausea, abdominal pain, hypoglycemia, hypotension, and shock) in a subsequent stressful event $(2,3)$. Therefore, stimulation tests are used in the assessment of the hypothalamic-pituitary-adrenal (HPA) axis. The widely used standard short Synacthen (250 $\mu \mathrm{g}$ tetracosactrin) test induces supraphysiological adrenocorticotropin (ACTH) concentrations, providing false-normal cortisol responses and low sensitivity in identifying acute-onset adrenal insufficiency. The insulin-induced hypoglycemia test is generally agreed to be the reference standard for testing the HPA adequacy in response to stress (4). However, this test is labor intensive and contraindicated in some patients. The low-dose $(1 \mu \mathrm{g})$ ACTH test has recently been introduced and proved to be sensitive in revealing partial adrenal insufficiency by providing physiological adrenocortical stimulation $(5,6)$. The results of the low-dose $(1 \mu \mathrm{g})$ ACTH test correlate closely with those of the reference test for the function of the HPA axis (7), and are superior to the standard $(250 \mu \mathrm{g})$ ACTH test (8). However, the literature remains controversial about the cut-off point representing a normal adrenal 
response to $1 \mu \mathrm{g}$ ACTH, and about the sensitivity of the low-dose $(1 \mu \mathrm{g})$ ACTH test in the diagnosis of secondary hypoadrenalism (9).

During surgical procedures plasma ACTH and cortisol concentrations rise rapidly to maintain the homeostasis of, among others, blood oxygen, blood $\mathrm{pH}$, and body temperature. The quantitative rise in postoperative cortisol levels correlates with the extent of surgery and the illness severity scores (10). A relative deficiency of the cortisol stress response can cause hemodynamic abnormalities that mimic hypovolemic or septic shock and may contribute to a fatal outcome (1).

The purpose of our study was to assess the adrenal response to the low-dose $(1 \mu \mathrm{g}) \mathrm{ACTH}$ test in patients with no history of adrenal disease undergoing coronary artery bypass grafting (CABG) with cardiopulmonary bypass $(\mathrm{CPB})$ which constitutes a defined and comparable stress situation. We also aimed to find out whether the adrenal function correlated with clinical outcome.

\section{Subjects and methods}

\section{Participants}

Between November 1999 and March 2000, we undertook a prospective cohort study in a large urban hospital, including patients undergoing elective CABG with CPB. We excluded patients with a history of exogenous glucocorticoid treatment (i.e. for oral, intravenous, intramuscular, and intra-articular forms of glucocorticoid treatment - topical and inhaled glucocorticoids during the last 6 months), endocrine diseases (i.e. Addison's disease, Cushing's disease, and adrenal metastases or hemorrhages), acute myocardial infarction, sepsis, and multiorgan failure. Etomidate was not allowed in the anesthetic regime and was considered an exclusion criterion. The lowdose $(1 \mu \mathrm{g})$ ACTH test was performed in 45 patients (16 women and 29 men; mean age ( \pm S.D.) $61 \pm 13$ years). Baseline characteristics are shown in Table 1. The study was approved by the local institutional ethics committee, and informed consent was obtained from all participants.

\section{Materials and methods}

The following anesthetic induction regime was used: midazolam $(7.5 \mathrm{mg})$, thiopentone $(2 \mathrm{mg} / \mathrm{kg})$, fentanyl $(3 \mu \mathrm{g} / \mathrm{kg})$, and rocuronium bromide $(1 \mathrm{mg} / \mathrm{kg})$. Continuous propofol and fentanyl infusions were used for maintenance of anesthesia. Monitoring included electrocardiography, pulse oximetry, end-tidal $\mathrm{CO}_{2}$, arterial catheter, and central venous pressure. Antibiotic prophylaxis consisted of cefuroxime $(1.5 \mathrm{~g}$, t.i.d.) for $48 \mathrm{~h}$. After heparin injection (300 IU/kg), moderate hypothermic CPB was achieved using a hollow fiber oxygenator. Myocardial preservation was performed with intermittent infusion of crystalloid cardioplegic solution and topical ice application.

For the low-dose $(1 \mu \mathrm{g})$ ACTH test, a bolus i.v. injection of $1 \mu \mathrm{g}(1-24)$-corticotropin (tetracosactrin, Synacthen, Novartis Pharma, Berne, Switzerland) was given. One vial of $250 \mu \mathrm{g}$ tetracosactrin was diluted in sterile saline solution to a concentration of $1 \mu \mathrm{g} / \mathrm{ml}$, filtered in plastic syringes, and stored at $4{ }^{\circ} \mathrm{C}$ as described elsewhere (5). The tests were carried out on the day before the operation (day -1 ), immediately after the operation on the intensive care unit (ICU) (day 0), on the next 2 days in the ICU

Table 1 Baseline characteristics of participating patients. Results are means \pm S.D. or median (interquartile range).

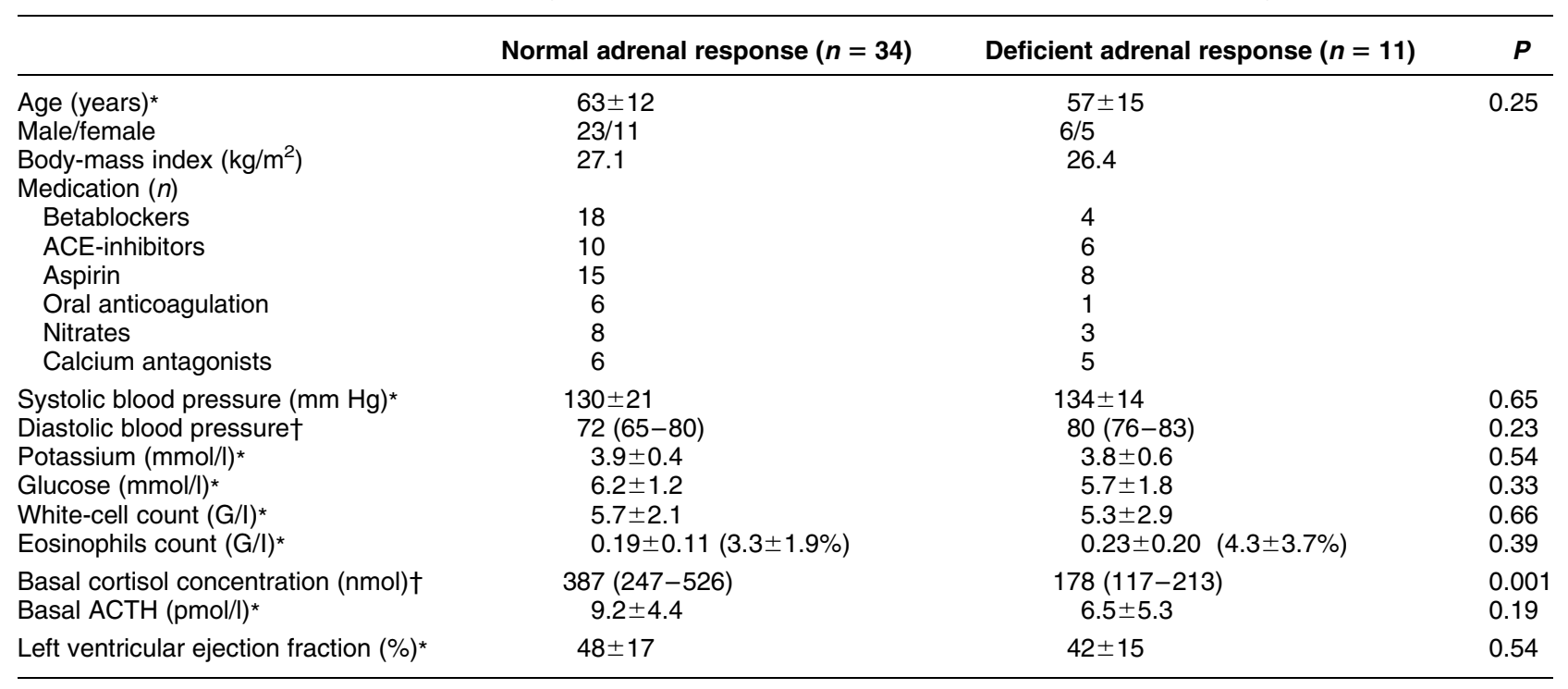

*Mean \pm S.D.; difference tested by Student's $t$-test; †median (interquartile range): difference tested by Mann-Whitney test.

$\mathrm{G} / \mathrm{l}$, the absolute number of eosinophils $\left(=10^{9} / \mathrm{l}\right)$, corresponding to the relative number (percentage) of $3.3 \pm 1.9 \%$ and $4.3 \pm 3.7 \%$, respectively. 
(day 1 and day 2), and before discharge from the hospital. Blood samples were taken for the measurement of basal plasma cortisol concentration, glucose, electrolytes, and white-cell count; $1 \mu \mathrm{g}$ ACTH was administered intravenously via a cannula (Vasofix Braunüle, B Braun, Melsungen, Germany) on day -1 and before discharge, and via a central venous line on days 0,1 , and 2, and another blood sample was taken after $30 \mathrm{~min}$ for measurement of stimulated plasma cortisol concentrations. The tests were carried out in the afternoon on day -1 and day 0 , and at $0800 \mathrm{~h}$ on day 1 , day 2 , and on the day of discharge. The following clinical and hemodynamic parameters were monitored: duration of ischemia and time on $\mathrm{CPB}$, time to weaning, left ventricular ejection fraction before and after the operation, glucose, electrolytes, pulse rate, blood loss, bleeding volume, volume replacement, and need for vasopressor drugs.

Plasma cortisol was measured by fluorometric enzyme-immunoassay (Dade Stratus, AHS, Merz+Dade, Munich, Germany). A normal response to i.v. ACTH was defined as a stimulated plasma cortisol concentration above $550 \mathrm{nmol} / \mathrm{l}(20 \mu \mathrm{g} / \mathrm{dl})$. A deficient response to ACTH was defined as a plasma cortisol concentration below $550 \mathrm{nmol} / \mathrm{l} 30 \mathrm{~min}$ after the injection of $1 \mu \mathrm{g}$ ACTH. The intra- and interassay coefficients of variation were $5.1 \%$ and $4.1 \%$ respectively. The sensitivity of the assay was $7.2 \mathrm{nmol} / \mathrm{l}(0.3 \mu \mathrm{g} / \mathrm{dl})$. The assay was highly specific for cortisol with low crossreactivity to other glucocorticoids. (To convert values for plasma cortisol concentrations from nanomoles per liter to micrograms per deciliter, multiply by 0.036 .)

Blood glucose levels were measured by the hexokinase method (Gluco-quant, Boehringer Mannheim, Mannheim, Germany), and serum potassium concentrations were measured by direct potentiometry.

\section{Analysis of data}

All statistical analyses were performed using SigmaStat, Statistical Analysis System, version 1.0 (Jandel Scientific Software, San Rafael, CA, USA). In the baseline characteristics with a normal distribution (checked by Kolmogorov-Smirnov test) the results are given as means ( \pm S.D.) and the Student's $t$-test was used to compare groups. Otherwise the results are given as median (interquartile range (IQR)) and the Mann-Whitney rank sum test was performed. Serial measurements were analyzed by one-way ANOVA followed by Dunn's test for multiple comparisons. Relationships between variables were analyzed by linear regression analysis. $P<0.05$ was considered as the limit of statistical significance.

\section{Results}

On day $-1,34$ of the $45(75 \%)$ study patients had stimulated plasma cortisol concentrations above
$550 \mathrm{nmol} / \mathrm{l}$ and, therefore, were classified as having a normal adrenal response (mean ( \pm S.D.) stimulated plasma cortisol concentrations $726 \pm 134 \mathrm{nmol} / \mathrm{l})$. Eleven patients $(25 \%)$ had stimulated plasma cortisol concentrations below this cut-off and were defined as having (partial) adrenal insufficiency $(384 \pm 152 \mathrm{nmol} / \mathrm{l})$. The mean basal plasma cortisol concentrations were also significantly lower in patients with deficient adrenal response (178 (IQR: 117-213) vs $387(247-526) \mathrm{nmol} / \mathrm{l}, P=0.001)$. On day 0 , basal and stimulated plasma cortisol concentrations were lower in the patients who had a deficient adrenal response on day -1 , but the difference was no longer statistically significant (basal cortisol concentrations $408 \pm 216$ vs $487 \pm 272 \mathrm{nmol} / \mathrm{l}, \quad P=0.41$; stimulated cortisol concentrations $642 \pm 252$ vs $735 \pm 239 \mathrm{nmol} / \mathrm{l}, P=0.29)$. However, on day 1 , day 2 , and on the day of discharge, the stimulated plasma cortisol concentrations were again significantly reduced in the patients who started with an inadequate adrenal response on the day before the operation: $756 \pm 205$ vs $949 \pm 259 \mathrm{nmol} / \mathrm{l}$ on day $1, P=0.03$; $779 \pm 404$ vs $933 \pm 265 \mathrm{nmol} / \mathrm{l}$ on day 2, $P=0.03$; $698 \pm 201$ vs $854 \pm 186 \mathrm{nmol} / \mathrm{l}$ on the day of discharge, $P=0.05$ (Fig. 1). There was a close correlation between the stimulated plasma cortisol levels and the increment of the cortisol levels after intravenous ACTH (Fig. 2). Patients with a normal adrenal response in the preoperative setting had peak cortisol concentrations on day 1 , whereas the maximum plasma cortisol concentrations in patients with an insufficient

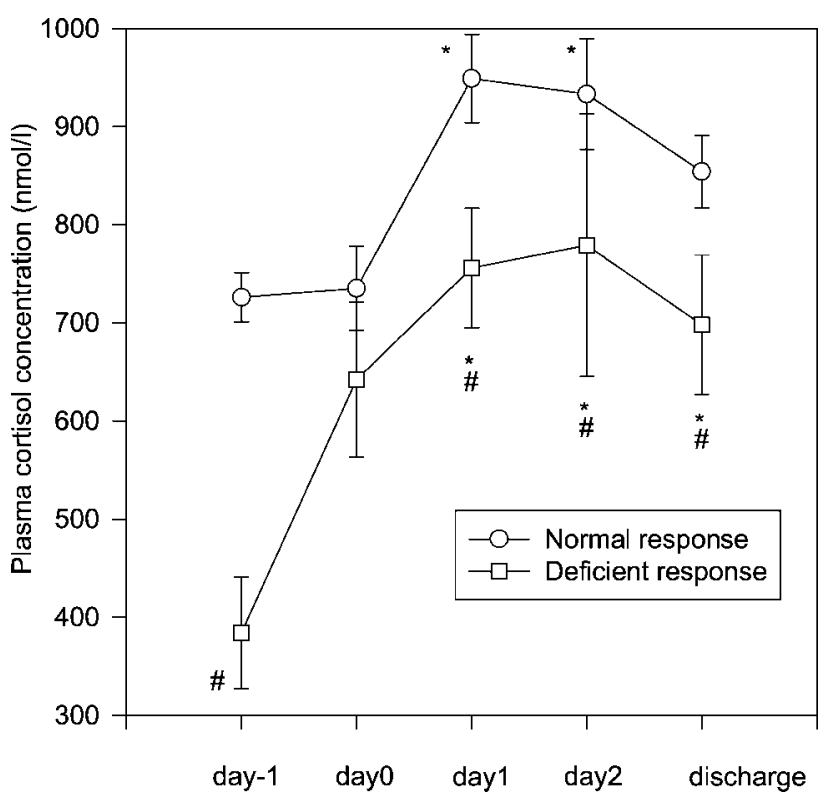

Figure 1 Stimulated plasma cortisol levels in patients undergoing coronary artery bypass grafting with normal $(n=34)$ and deficient $(n=11)$ adrenal response to $1 \mu \mathrm{g} \mathrm{ACTH}$. Values are means \pm S.E.M. ${ }^{\star} P<0.05$ compared with day -1 . \#P<0.05 compared with normal adrenal response. 


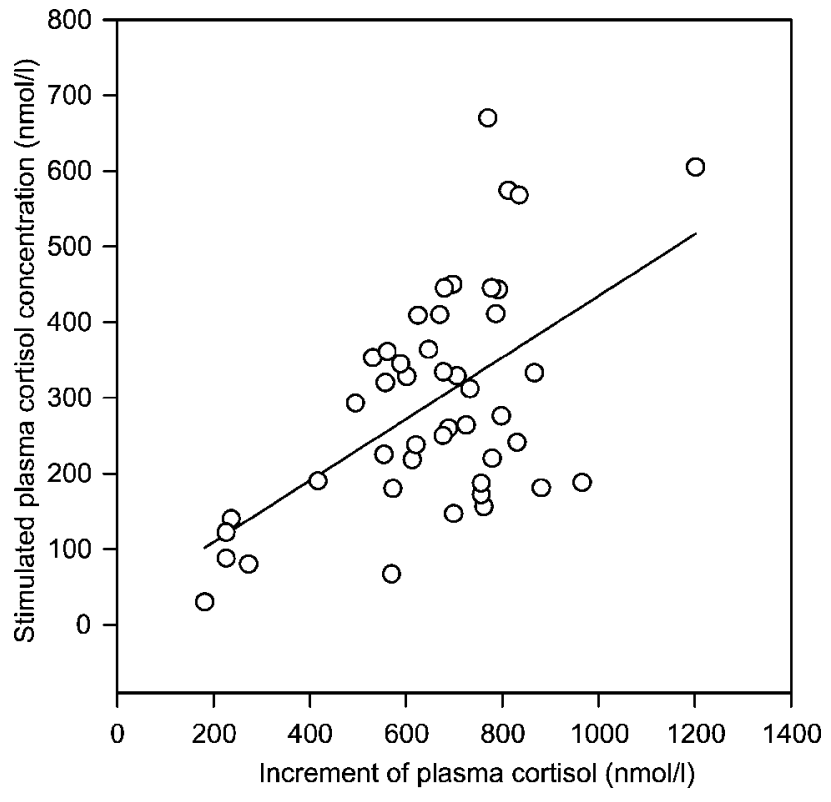

Figure 2 Stimulated plasma cortisol levels vs increment of plasma cortisol levels after $1 \mu \mathrm{g} \mathrm{ACTH}$ in patients undergoing coronary artery bypass grafting $(n=45)$. $P<0.001, r=0.55$.

adrenal response were measured on day 2. Table 2 illustrates the clinical and hemodynamic differences between patients with normal and deficient adrenal response to $1 \mu \mathrm{g}$ ACTH.

There were significant correlations between stimulated plasma cortisol concentrations and bleeding volume $(r=-0.50, P=0.002)$ (Fig. 3), and volume balance ( $r=0.41, P=0.015)$ (Fig. 4$)$. There were no correlations between plasma cortisol concentrations and age, time to weaning $(r=0.16, P=0.35)$, duration of ICU and hospital stay $(r=0.21, P=0.25)$, use of vasopressor drugs $(r=0.007, P=0.96)$, time of ischemia $(r=0.10, P=0.55)$ and time on $\mathrm{CPB}$ $(r=0.07, \quad P=0.68)$, blood pressure $(r=0.01$, $P=0.93)$, pulse rate $(r=0.002, P=0.93)$, left ventricular ejection fraction $(r=0.13, P=0.70)$, and electrolytes $(r=0.11, P=0.54)$.

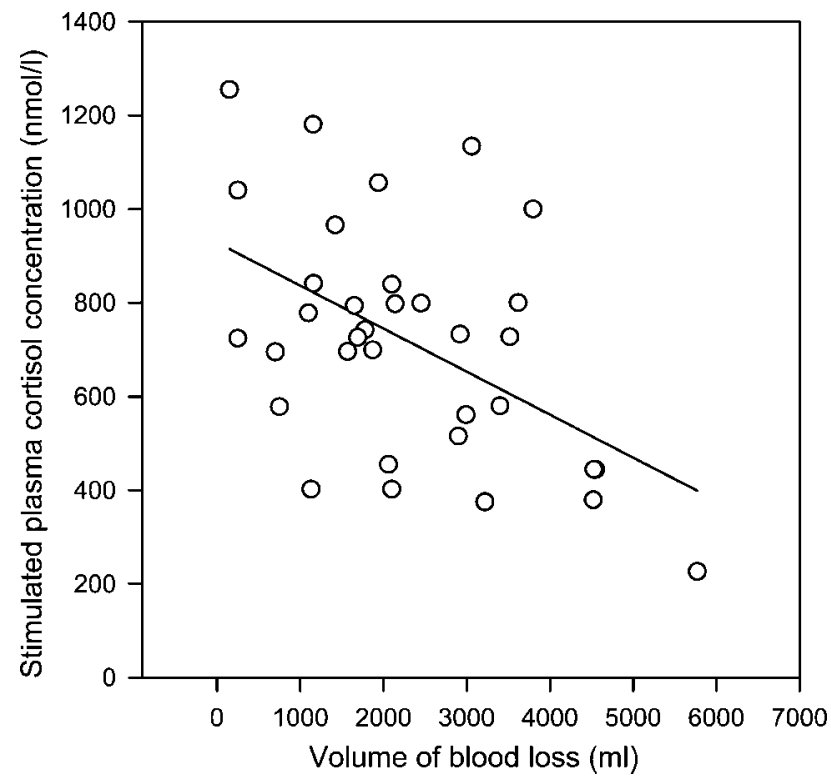

Figure 3 Correlation between the adrenal response to the low-dose $(1 \mu \mathrm{g})$ ACTH test and bleeding volume in the first $48 \mathrm{~h}$ in patients undergoing coronary artery bypass grafting. $P=0.002$, $r=-0.50$.

\section{Discussion}

The responsiveness of the hypothalamic-pituitaryadrenal axis to stress is essential for survival. The adrenal cortisol secretion is regulated by continuous tropic ACTH stimulation and varies little in the absence of stress. In case of severe illness, trauma and major surgery, however, the activation of the HPA axis results in an almost 10-fold increase in cortisol secretion in order to adapt to stress and to maintain homeostasis (1). This rise is essential for maintaining vascular tone, endothelial integrity and the distribution of body water. Cortisol, furthermore, enhances sensitivity to the pressor effects of the catecholamines and mobilizes energy via gluconeogenesis, proteolysis, and lipolysis. Although the incidence of complete adrenal insufficiency after routine surgery and in severely ill

Table 2 Clinical and hemodynamic outcome in patients with normal and deficient adrenal response to $1 \mu \mathrm{g}$ ACTH. Results are means \pm S.D. or median (interquartile range).

\begin{tabular}{|c|c|c|c|}
\hline & Normal adrenal response $(n=34)$ & Deficient adrenal response $(n=11)$ & $\boldsymbol{P}$ \\
\hline Time of ischemia (min)† & $62(51-73)$ & $60(59-66)$ & 0.78 \\
\hline Time on CPB (min)* & $94 \pm 29$ & $99 \pm 28$ & 0.68 \\
\hline Use of vasopressor drugs $(\mathrm{h}) \dagger$ & $24(8-57)$ & $26(6-72)$ & 0.50 \\
\hline Time to weaning $(\mathrm{h}) \dagger$ & $13(9.5-16.8)$ & $12(7.2-19.8)$ & 0.75 \\
\hline Volume of blood loss (ml)* & $1770 \pm 867$ & $2082 \pm 1603$ & 0.47 \\
\hline Volume balance $(\mathrm{ml})^{\star}$ & $-182 \pm 1266$ & $-722 \pm 1904$ & 0.30 \\
\hline Length of hospital stay (days)† & $12(11-13.5)$ & $12(12-14)$ & 0.40 \\
\hline
\end{tabular}

*Mean \pm S.D.; difference tested by Student's $t$-test; †median (interquartile range): difference tested by Mann-Whitney test. 


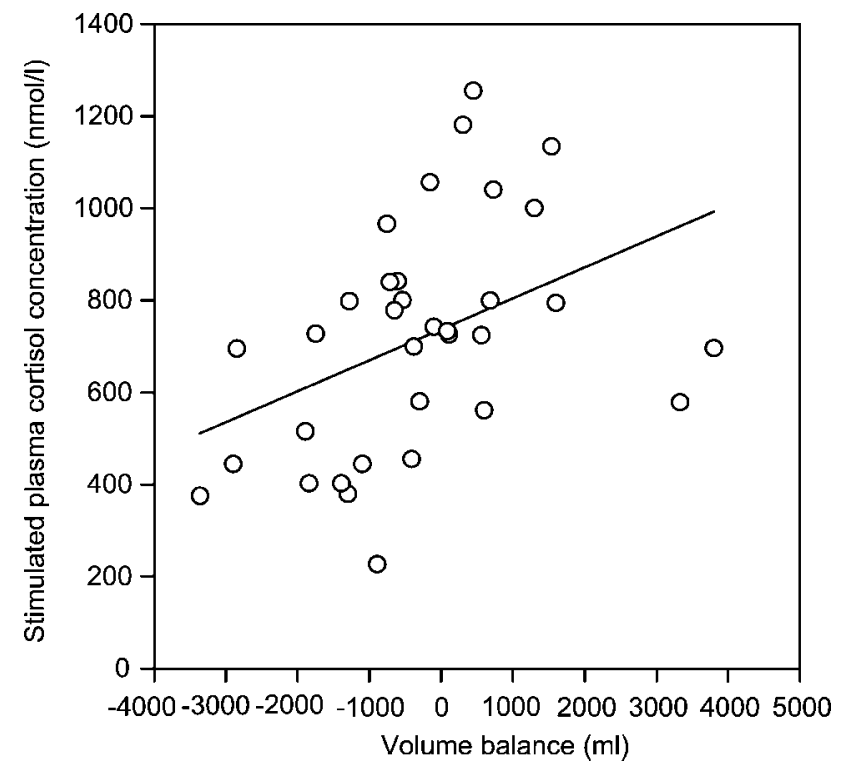

Figure 4 Correlation between the adrenal response to the low-dose $(1 \mu \mathrm{g})$ ACTH test and the volume balance in the first $48 \mathrm{~h}$ in patients undergoing coronary artery bypass grafting. $P=0.015, r=0.41$.

patients is low $(10,11)$, occurring in 2 to $3 \%$ of the patients, the adrenocortical production of cortisol may be impaired and represent an occult or relative adrenal insufficiency $(12-14)$. Evidence of the fatal role of an occult relative adrenal insufficiency has been provided by recent reports of hydrocortisone administration in critically ill patients (15), but also by the massive rise of mortality with the use of etomidate in the ICU of the University Hospital of Glasgow. Etomidate, a short acting hypnotic drug, inhibits adrenal $11 \beta$-hydroxylase, which converts deoxycortisol to cortisol, and thus induces adrenal insufficiency $(16,17)$. Among the various factors leading to relative adrenal insufficiency, treatment with exogenous glucocorticoids is the most common (18). It is well recognised that adrenal function shows little correlation with the dose and duration of glucocorticoid treatment $(19,20)$. However, even after a short period of glucocorticoid treatment (i.e. a median duration of less than 12 days) the adrenal response was suppressed in $45 \%$ of the patients (20).

In the evaluation of the HPA axis, results of the low dose $(1 \mu \mathrm{g})$ ACTH test correlate well with those of the insulin-induced hypoglycemia test. A single (stimulated) plasma cortisol concentration measured $30 \mathrm{~min}$ after the administration of $1 \mu \mathrm{g}$ ACTH reliably reflects adrenal function without false normal results and, therefore, eliminates the shortcomings of the standard short $(250 \mu \mathrm{g})$ ACTH test.

In the present study, the low dose $(1 \mu \mathrm{g})$ ACTH test revealed a (partially) deficient adrenal response in $25 \%$ of 45 patients undergoing elective coronary artery bypass grafting. In these patients not only the magnitude of cortisol secretion but also the kinetics of the adrenal response were significantly altered, i.e. their maximum plasma cortisol concentrations were reached $24 \mathrm{~h}$ later than patients with normal adrenal function. The reason for the surprisingly high proportion of asymptomatic patients with partial adrenal insufficiency is unknown. Patients with possible causes for suppression of adrenal function such as neoplasia, bleeding disorders, infectious and polyglandular disease have been excluded. There were no significant differences in the baseline characteristics of the patients. However, the significant time delay compared with normal patients in these with a deficient adrenal response points to a potential relevance of these findings given the prognostic value of the cortisol response to ACTH (21). Among various clinical outcome parameters a correlation was clearly demonstrated between adrenal function and blood loss and volume balance respectively. The increased blood loss in patients with an inadequate adrenal response may be related to the plasma concentrations of factor VIII and von Willebrand factor, which are known to be increased in hypercortisolism (22). The diminished mineralocorticoid potency of deficient adrenal glands may explain the negative volume balance. However, it is possible that more subtle clinical effects of partial adrenal insufficiency, such as the reduced or absent need for vasopressor drugs following hydrocortisone replacement in patients with impaired adrenal function will be detected in larger study populations.

Symptoms and signs of acute adrenal crisis (i.e. dehydration, fever, confusion, nausea, abdominal pain, hypoglycemia, hypotension, and shock) may occur in the patients with partial adrenal insufficiency exposed to stress. The diagnosis is easily missed or delayed because the clinical findings in acute adrenal insufficiency may be interpreted as complications of surgery. Parenteral administration of 100 to $300 \mathrm{mg}$ hydrocortisone should be given as soon as the diagnosis of acute adrenal insufficiency is suspected.

A deficient adrenal response to $1 \mu \mathrm{g}$ ACTH is frequent in patients undergoing elective coronary artery bypass grafting who are asymptomatic as far as endocrine disease is concerned. The adrenal function in these patients differs both in the magnitude of the cortisol secretion and in the time course, with significantly blunted and delayed peak cortisol concentrations. Regulation of volume balance and the amount of blood loss correlated with the adequacy of the adrenal response.

\section{Acknowledgements}

The study was supported by an institutional fund of the Department of Internal Medicine (Fortbildungsfond Medizinische Klinik, Kantonsspital Luzern). We would also like to thank the ICU staff of the Kantonsspital Luzern. 


\section{References}

1 Lamberts SWJ, Bruining HA \& de Jong FH. Corticosteroid therapy in severe illness. New England Journal of Medicine 1997337 1285-1292.

2 Hägg E, Asplund K \& Lithner F. Value of basal plasma cortisol assays in the assessment of pituitary-adrenal insufficiency. Clinical Endocrinology 198726 221-226.

3 Christy NP. Pituitary-adrenal function during corticosteroid therapy. New England Journal of Medicine 1992326 266-267.

4 Grinspoon SK \& Biller BMK. Laboratory assessment of adrenal insufficiency. Journal of Clinical Endocrinology and Metabolism 199479 923-931.

5 Dickstein G, Schechner C, Nicholson WE, Rosner I, Shen-Orr Z, Adawi $\mathrm{F}$ et al. Adrenocorticotropin stimulation test: effects of basal cortisol level, time of day and suggested new sensitive low dose test. Journal of Clinical Endocrinology and Metabolism 1991 $72773-778$.

6 Daidoh H, Morita H, Mune T, Murayama M, Hanafusa J, Ni H et al. Responses of plasma adrenocortical steroids to low dose ACTH in normal subjects. Clinical Endocrinology 199543 311-315.

7 Rasmuson S, Olsson T \& Hägg E. A low dose ACTH test to assess the function of the hypothalamic-pituitary-adrenal axis. Clinical Endocrinology $1996 \mathbf{4 4} 151-156$.

8 Thaler LM \& Blevins LS. The low dose (1- $\mu \mathrm{g})$ adrenocorticotropin stimulation test in the evaluation of patients with suspected central adrenal insufficiency. Journal of Clinical Endocrinology and Metabolism 199883 2726-2729.

9 Dickstein G. Hypothalamo-pituitary-adrenal axis testing: nothing is sacred and caution in interpretation is needed. Clinical Endocrinology $20014515-16$.

10 Mohler JL, Michael KA, Freedman AM, McRoberts JW \& Griffen WO Jr. The evaluation of postoperative function of the adrenal gland. Surgical Gynecology and Obstetrics 1985161 551-556.

11 Drucker D \& McLaughlin J. Adrenocortical dysfunction in acute medical illness. Critical Care and Medicine 198614 789-791.

12 McKee JI \& Finlay WEI. Cortisol replacement in severely stressed patients. Lancet 1983 I $\mathbf{4 8 4}$
13 Baldwin WA \& Allo M. Occult hypoadrenalism in critically ill patients. Archives of Surgery $1993 \mathbf{1 2 8} 673-676$.

14 Kidess AI, Caplan RH, Reynertson RH, Wickus GG \& Goodnough DE. Transient corticotropin deficiency in critical illness. Mayo Clinical Proceedings 199368 435-441.

15 Briegel J, Forst H, Kellermann W, Haller M \& Peter K. Haemodynamic improvement in refractory septic shock with cortisol replacement therapy. Intensive Care and Medicine 1992 18318.

16 Ledingham IM \& Watt I. Influence of sedation on mortality in critically ill multiple trauma patients. Lancet 1983 I 1270.

17 de Jong FH, Mallios C, Jansen C, Scheck PAE \& Lamberts SWJ. Etomidate suppresses adrenocortical function by inhibition of 11(beta)-hydroxylation. Journal of Clinical Endocrinology and Metabolism 198459 1143-1147.

18 Melby JC. Systemic corticosteroid therapy: pharmacology and endocrinologic considerations. Annals of Internal Medicine 1974 $81505-512$.

19 Schlaghecke R, Kornely E, Santen RT \& Ridderskamp P. The effect of longterm glucocorticoid therapy on pituitary-adrenal responses to exogenous corticotropin-releasing hormone. New England Journal of Medicine 1992326 226-230.

20 Henzen C, Suter A, Lerch E, Urbinelli R, Schorno XH \& Briner VA. Suppression and recovery of adrenal response after short-term, high-dose glucocorticoid treatment. Lancet $2000355542-545$.

21 Annane D, Sebille V, Troche G, Raphael JC, Gajdos P \& Bellissant E. A 3-level prognostic classification in septic shock based on cortisol levels and cortisol response to corticotropin. JAMA $20002831038-1045$

22 Casonato A, Pontara E, Boscaro M, Sonino N, Sartorello F, Ferasin $S$ et al. Abnormalities of von Willebrand factor are also part of the prothrombotic state of Cushing's syndrome. Blood Coagulation and Fibrinolysis 199910 145-151.

Received 15 January 2003

Accepted 2 April 2003 